\title{
Vancomycin versus cefazolin prophylaxis for cardiac surgery in the setting of a high prevalence of methicillin- resistant staphylococcal infections
}

\author{
R. Finkelstein, $M D^{a, b}$ \\ G. Rabino, $\mathrm{MA}^{\mathrm{a}}$ \\ T. Mashiah, $\mathrm{MA}^{\mathrm{a}}$ \\ Y. Bar-El, MDa,b \\ Z. Adler, $M D^{\mathrm{a}}$ \\ V. Kertzman, $\mathrm{MD}^{\mathrm{a}}$ \\ 0 . Cohen ${ }^{\mathrm{a}}$ \\ S. Milo, MD ${ }^{a, b}$
}

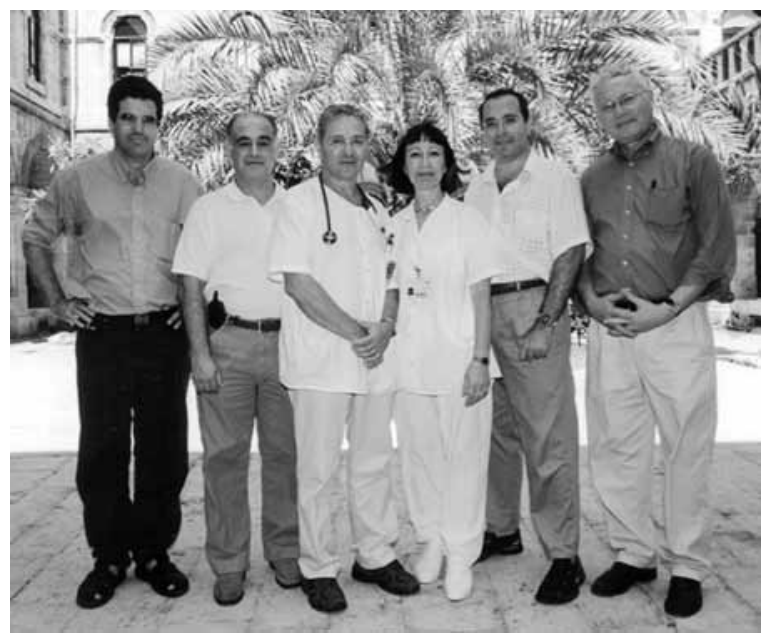

Objective: This study was undertaken to compare the efficacy of vancomycin prophylaxis with that of cefazolin in preventing surgical site infections in a tertiary medical center with a high prevalence of methicillin-resistant staphylococcal infections.

Methods: All adult patients ( $\geq 18$ years) scheduled for cardiac surgery requiring sternotomy were randomly assigned to receive vancomycin ( $1 \mathrm{~g}$ every 12 hours) or cefazolin ( $1 \mathrm{~g}$ every 8 hours). Prophylaxis was started during the induction of anesthesia and continued for only 24 hours. Patients were followed up for at least 30 days (1 year for those receiving a cardiac implant). Surgical site infections were stratified according to the National Nosocomial Infections Surveillance System risk index.

Results: Of the 885 patients included in the study, 452 received vancomycin and 433 received cefazolin. The overall surgical site infection rates were similar in the two groups ( 43 cases in the vancomycin group, $9.5 \%$, vs 39 cases in the cefazolin group, $9.0 \%, P=.8$ ). Superficial and deep incisional surgical site infection rates were also similar in the two groups. There was a trend toward more frequent organ-space infections and infections with $\beta$ lactam-resistant organisms among patients receiving cefazolin, but this trend did not reach statistical significance. In contrast, surgical site infections caused by methicillin-susceptible staphylococci were significantly more common in the vancomycin group (17 cases, $3.7 \%$, vs 6 cases, $1.3 \%, P=.04$ ). The durations of postoperative hospitalization and the mortalities were similar in the two groups.

From Rambam Medical Center ${ }^{\mathrm{a}}$ and Technion-Israel Institute of Technology, ${ }^{b}$ Haifa, Israel.

Received for publication April 23, 2001; revisions requested June 6, 2001; revisions received July 12, 2001; accepted for publication July 20, 2001.

Address for reprints: R. Finkelstein, MD, Infectious Diseases Unit, Rambam Medical Center, Haifa 31096, Israel (E-mail: rfinkelstein@rambam.health.gov.il).

J Thorac Cardiovasc Surg 2002;123:326-32

Copyright (C) 2002 by The American Association for Thoracic Surgery

$0022-5223 / 2002 \$ 35.00+0 \quad \mathbf{1 2 / 1 / 1 1 9 6 9 8}$

doi:10.1067/mtc. 2002.119698
Conclusions: This trial suggests that vancomycin and cefazolin have similar efficacy in preventing surgical site infections in cardiac surgery.

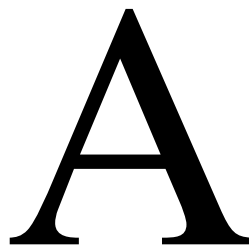

n estimated 468,000 coronary artery bypass grafting (CABG) procedures and more than 60,000 valve implantations are performed annually in the United States. ${ }^{1,2}$ Surgical site infections (SSIs), particularly organ-space infections, have serious implications when associated with these operations because of the substantial morbidity, mortality, and expense that they add to the health care system. The benefits of antibiotic prophylaxis in cardiovascular surgery have been clearly demonstrated in several placebo-controlled studies, ${ }^{3-6}$ but the choice of the 
optimal agent remains controversial. Cephalosporins have been the mainstay of prophylaxis in cardiac surgery because staphylococci are the most common organisms isolated from both vein donor sites and chest wound infections. ${ }^{7,8} \mathrm{~A}$ recent review, sponsored by the Infectious Diseases Society of America and endorsed by both it and the Surgical Infection Society, recommended, "Vancomycin can be given instead of cefazolin to patients who are allergic to cephalosporins or in settings where infections with methicillin-resistant Staphylococcus aureus (MRSA) are prevalent." At the time this study was started, only one published clinical trial had investigated the efficacy of vancomycin relative to that of cephalosporins in preventing SSIs in cardiovascular surgery. ${ }^{10}$ That double-blind control study showed the superiority of vancomycin to cefazolin in preventing thoracic SSIs other than mediastinitis. This trial was undertaken to compare the efficacy of cefazolin and vancomycin in preventing SSIs in cardiovascular surgery at a large university hospital with a high prevalence of MRSA infections.

\section{Methods \\ Patients}

The trial was conducted between January 1997 and December 1999 at Rambam Medical Center, Haifa, Israel, where approximately 400 cardiac operations are performed annually on adult patients. MRSA infections have been highly prevalent in our institution for several years. ${ }^{11}$ A recently published consensus panel's definitions for discriminating high rates of MRSA transmission have suggested a threshold of 0.5 new nosocomial cases of MRSA per 100 admissions for hospitals with at least 500 beds. ${ }^{12}$ According to our computerized records, in 1995 and 1996 there were 3.0 and 2.6 new cases of MRSA infection or colonization, respectively, per 100 admissions in our cardiac surgery ward, easily meeting the criterion for high transmission of MRSA.

The study was approved by the local ethical review committee. Informed consent was not required because we had been using both drugs for prophylaxis in cardiovascular surgery before the trial. All adult patients ( $\geq 18$ years) scheduled for cardiac surgery requiring sternotomy were considered eligible for the trial. Exclusion criteria included the presence of active infection, the use of antibiotics within 2 weeks before the operation, and a previous cardiac operation requiring sternotomy within 1 year of enrollment in this trial.

\section{Random Assignment and Antibiotic Regimens}

Random assignment was performed according to the last digit of the patient's national identification number (similar to US social security number). Patients whose identification number ended in an even digit were scheduled to receive $1.0 \mathrm{~g}$ vancomycin intravenously at the induction of the anesthesia over a period of 60 minutes and a similar dose 12 hours later. Patients whose identification number ended in an odd digit were scheduled to receive $1 \mathrm{~g}$ cefazolin intravenously over a period of 20 to 30 minutes at the induction of the anesthesia and two additional similar doses at 8hour intervals. Because the timing of administration of prophy- laxis is of great importance in preventing SSIs,${ }^{13}$ we defined the antibiotic regimen as "preoperative prophylaxis" if the antibiotic drug was administered in an optimal period of 2 hours or less before the first surgical incision.

\section{Surgical Preparation and Technical Details}

The patients showered with a $7.5 \%$ povidone-iodine scrub (Polydine Cleanser; Fisher Pharmaceutical Laboratories, Tel Aviv, Israel) the night before the scheduled operation and again on the morning of the operation. The sites of operation were depilated on the morning of the operation with a hair-removing cream (Vito; Heibel Co, Hadera, Israel). In the operating room all operative sites were scrubbed with the povidone-iodine soap solution and then painted with a $10 \%$ povidone-iodine-ethanol tincture (Polydine Tincture; Fisher Pharmaceutical Laboratories). The area of sternotomy was covered with an iodine membrane (Loban; 3M Health Care, St Paul, Minn). All operations were done under conventional cardiopulmonary bypass and moderate hypothermia (rectal temperature $28^{\circ} \mathrm{C}-30^{\circ} \mathrm{C}$ ) with a membrane oxygenator (SpiralGold; Baxter Healthcare Corporation CardioVascular Group, Irvine, Calif). Myocardial protection was achieved with short antegrade and continuous retrograde undiluted blood cardioplegia. The internal thoracic arteries were used in $96 \%$ of the patients undergoing CABG operations and were harvested either pedicled or skeletonized according to the surgeon's preference with low-grade diathermy. The greater saphenous vein was harvested through a single skin incision by means of standard surgical procedures. All subcutaneous tissues were approximated with continuous absorbable multifilament sutures (Coated Vicryl; Ethicon, Inc, Somerville, $\mathrm{NJ}$ ), and skin wounds were closed with stainless steel clips (Weck Closure Systems, Research Triangle Park, NC). All operations were performed by the same team headed by four experienced cardiac surgeons (Y.B., Z.A., V.K., S.M.).

\section{Patient Evaluation}

During hospitalization, patients were evaluated daily by cardiac surgeons and three times a week by an infection control nurse. At the discretion of the attending physician, an infectious diseases specialist was also involved in the evaluation and treatment of patients. Cultures were obtained as clinically indicated and processed in the hospital's microbiology laboratory according to standard procedures. All patients were followed up for the appearance of postdischarge SSI with at least two visits, the first 1 week after discharge and the second 3 weeks later. Follow-up was done in the hospital's cardiac surgery outpatient clinics with the presence of an infection control nurse or infectious diseases physician. Patients receiving a cardiac implant were followed up for at least 1 year. Six patients who did not return to the outpatient clinic were contacted by telephone by the infection control nurse.

\section{Definitions}

Nosocomial SSIs were defined according to the Centers for Disease Control and Prevention definitions. ${ }^{14}$ The criteria are described here.

Superficial SSI. This was an infection involving only skin and subcutaneous tissue with at least one of the following: purulent drainage from the incision, positive results of incisional culture, 
TABLE 1. Characteristics of 885 patients receiving cefazolin or vancomycin for prophylaxis in cardiovascular surgery

\begin{tabular}{lcc}
\hline & \multicolumn{2}{c}{ Study group } \\
\cline { 2 - 3 } & Vancomycin & Cefazolin \\
\hline Subjects (No.) & 452 & 433 \\
Male/female ratio & $325: 127$ & $311: 122$ \\
Age (y) & & \\
Mean \pm SD & $60.9 \pm 12.2$ & $61.2 \pm 12.8$ \\
Range & $18-85$ & $18-85$ \\
$60-69$ (No.) & $347(76.8 \%)$ & $323(75.1 \%)$ \\
$>70$ (No.) & $105(23.2 \%)$ & $108(24.9 \%)$ \\
Type of operation (No.) & & \\
CABG (chest and leg) & $329(72.7 \%)$ & $314(72.5 \%)$ \\
CABG (chest only) & $10(2.2 \%)$ & $12(2.7 \%)$ \\
Cardiac operation other than CABG & $81(17.9 \%)$ & $81(18.7 \%)$ \\
CABG and other cardiac operation & $32(7 \%)$ & $26(6 \%)$ \\
Cardiac implant & $90(19.9 \%)$ & $70(16.1 \%)$ \\
American Society of Anesthesiology & $413(91.3 \%)$ & $390(90 \%)$ \\
score $\geq 3$ (No.) & & \\
Duration of operation (min) & & \\
Mean \pm SD* & & \\
Range & $284.8 \pm 74$ & $273.7 \pm 70.9$ \\
$>5$ h (No.) & $110-620$ & $60-780$ \\
Risk index (No.) & $134(29.6 \%)$ & $187(27 \%)$ \\
Category 0 & & \\
Category 1 & $33(7.3 \%)$ & $35(8.1 \%)$ \\
Category 2 & $291(64.3 \%)$ & $289(66.7 \%)$ \\
Emergency operation (No.) & $128(28.3 \%)$ & $109(25.2 \%)$ \\
Stay before operation (d, mean \pm SD) & $47(10.4 \%)$ & $44(10.2 \%)$ \\
Preoperative prophylaxist (No.) & $366(92.4)$ & $369(94.5)$ \\
\hline
\end{tabular}

${ }^{*} P=.02$. No other differences were statistically significant at $P \leq .05$. tDefinition given in text.

and classic inflammatory signs that led to the incision being deliberately reopened by the surgeon unless results of an incisional culture were negative.

Deep incisional SSI. This was an infection involving deep soft tissues of the incision with at least one of the following: purulent drainage from the deep incision, a deep incision that spontaneously dehisced or was deliberately opened by the surgeon in the presence of fever (temperature $\geq 38^{\circ} \mathrm{C}$ ) or localized pain or tenderness unless results of an incisional culture were negative, and evidence of infection involving the deep incision found in direct examination or reoperation.

Mediastinitis. Mediastinitis was reported as a specific organspace SSI and was an infection characterized by one of the following: positive results of a culture obtained from mediastinal tissue or fluid during a surgical operation, a patient fever (temperature $\geq 38^{\circ} \mathrm{C}$ ), chest pain or sternal instability, mediastinal involvement suggested by a computed tomographic scan, and organisms cultured from the mediastinal area.

Sternal osteomyelitis. Sternal osteomyelitis was reported as a specific organ-space SSI and was indicated by a persistent puru-
TABLE 2. Outcomes of 885 patients receiving vancomycin or cefazolin prophylaxis for cardiovascular operations

\begin{tabular}{|c|c|c|}
\hline & $\begin{array}{c}\text { Vancomycin } \\
(n=452)\end{array}$ & $\begin{array}{l}\text { Cefazolin } \\
\text { (n= 433) }\end{array}$ \\
\hline \multicolumn{3}{|l|}{ Superficial incisional SSI (No.) } \\
\hline All & $25(5.5 \%)$ & $20(4.6 \%)$ \\
\hline Donor site & $7(1.5 \%)$ & $10(2.3 \%)$ \\
\hline Chest & $18(4 \%)$ & $10(2.3 \%)$ \\
\hline \multicolumn{3}{|l|}{ Deep incisional SSI (No.) } \\
\hline All & $12(2.6 \%)$ & $7(1.6 \%)$ \\
\hline Donor site & $2(0.4 \%)$ & $2(0.4 \%)$ \\
\hline Chest & $10(2.2 \%)$ & $5(1.2 \%)$ \\
\hline \multicolumn{3}{|l|}{ Organ-space SSI (No.) } \\
\hline All & $6(1.3 \%)$ & $12(2.7 \%)$ \\
\hline Mediastinitis & $5(1.1 \%)$ & $7(1.6 \%)$ \\
\hline Osteomyelitis & 0 & $3(0.7 \%)$ \\
\hline Endocarditis & $1(0.2 \%)$ & $2(0.4 \%)$ \\
\hline Pericarditis & 0 & 0 \\
\hline Any SSI (No.) & $43(9.5 \%)$ & $39(9.0 \%)$ \\
\hline $\begin{array}{l}\text { Duration of postoperative } \\
\text { hospitalization }(d \text {, mean } \pm S D)\end{array}$ & $8.7 \pm 8$ & $9.3 \pm 11$ \\
\hline Deaths (No.) & $13(2.9 \%)$ & $14(3.2 \%)$ \\
\hline
\end{tabular}

No differences were significant at $P \leq .05$.

lent drainage from the sternotomy confirmed by microbiologic and histopathologic findings.

Pericarditis. Pericarditis was reported as a specific organ-space SSI and was indicated by organisms cultured from pericardial tissue or fluid obtained by needle aspiration or during surgical operation.

Endocarditis. Endocarditis was reported as a specific organspace SSI and was defined according to the Duke criteria. ${ }^{15}$

\section{SSI Risk Stratification}

SSIs were stratified according to the National Nosocomial Infections Surveillance System risk index. ${ }^{16}$ Because all surgical wounds included in our study were classified as clean, the index values ranged from 0 to a maximum of 2 .

\section{Statistical Analysis}

Before the start of this trial, cefazolin had been used for many years as the routine prophylactic regimen for cardiovascular surgery in our institution. We estimated the number of patients that would be required for an adequate examination of the hypothesis that prophylaxis with vancomycin may result in a significant reduction in the overall rate of SSIs as follows. Because our rate of SSIs with cefazolin was not precisely known, we established this baseline rate by calculating SSI rates occurring during the first 12 months of the study. The overall SSI rate observed among 136 patients receiving cefazolin prophylaxis and included in the study during this period was $10.5 \%$. A total of 405 operations were required in each group for the study to have the ability to show a significant reduction of the SSI rate to 5\% with an $\alpha$ level of .20 and $\beta$ error of .05. The reduction to $5 \%$ was chosen as a maximal figure approximating the median of SSI rate reported by the 
TABLE 3. Microorganisms isolated according to surgical site infections and antibiotic prophylaxis* $\dagger$

\begin{tabular}{|c|c|c|c|c|c|c|c|c|}
\hline \multirow[b]{3}{*}{ Pathogens } & \multicolumn{4}{|c|}{ Vancomycin } & \multicolumn{4}{|c|}{ Cefazolin } \\
\hline & \multirow{2}{*}{$\begin{array}{c}\text { Leg }(n=9) \\
\text { Superficial } \\
\text { and deep } \\
\text { incisional } \\
(n=9)\end{array}$} & \multicolumn{2}{|c|}{ Chest $(n=34)$} & \multirow[b]{2}{*}{ Total $(n=43)$} & \multirow{2}{*}{$\begin{array}{c}\text { Leg }(n=12) \\
\text { Superficial } \\
\text { and deep } \\
\text { incisional } \\
(n=12)\end{array}$} & \multicolumn{2}{|c|}{ Chest $(n=27)$} & \multirow[b]{2}{*}{ Total $(n=39)$} \\
\hline & & $\begin{array}{c}\text { Superficial } \\
\text { and deep } \\
\text { incisional } \\
(\mathbf{n}=\mathbf{2 8})\end{array}$ & $\begin{array}{c}\text { Organ-space } \\
(n=6)\end{array}$ & & & $\begin{array}{c}\text { Superficial } \\
\text { and deep } \\
\text { incisional } \\
(n=15)\end{array}$ & $\begin{array}{c}\text { Organ-space } \\
(\mathrm{n}=12)\end{array}$ & \\
\hline \multicolumn{9}{|c|}{ Coagulase-negative staphylococci } \\
\hline All & $3(6.9 \%)$ & $9(20.9 \%)$ & $1(2.3 \%)$ & $13(30.2 \%)$ & $1(2.5 \%)$ & $4(10.2 \%)$ & $4(10.2 \%)$ & $9(23 \%)$ \\
\hline Methicillin-resistant & $1(2.3 \%)$ & $5(11.6 \%)$ & & $6(14 \%)$ & & $4(10.2 \%)$ & $4(10.2 \%)$ & $8(20.5 \%)$ \\
\hline Methicillin-susceptible & $2(4.6 \%)$ & $4(9.3 \%)$ & $1(2.3 \%)$ & $7(16.2 \%)$ & $1(2.5 \%)$ & & & $1(2.5 \%)$ \\
\hline \multicolumn{9}{|l|}{ S aureus } \\
\hline All & $3(6.9 \%)$ & $4(9.3 \%)$ & $5(11.6 \%)$ & $12(27.9 \%)$ & $4(10.2 \%)$ & $4(10.2 \%)$ & $4(10.2 \%)$ & $12(30.7 \%)$ \\
\hline Methicillin-resistant & & & $2(4.6 \%)$ & $2(4.6 \%)$ & $1(2.5 \%)$ & $2(5.1 \%)$ & $4(10.2 \%)$ & $7(17.9 \%)$ \\
\hline Methicillin-susceptible & $3(6.9 \%)$ & $4(9.3 \%)$ & $3(6.9 \%)$ & $10(23.2 \%)$ & $3(7.6 \%)$ & $2(5.1 \%)$ & & $5(12.8 \%)$ \\
\hline Enterococci & & $1(2.3 \%)$ & & $1(2.3 \%)$ & $1(2.5 \%)$ & $3(7.6 \%)$ & $1(2.5 \%)$ & $5(12.8 \%)$ \\
\hline Gram-negative bacilli & $3(6.9 \%)$ & $18(41.8 \%)$ & & $21(48.8 \%)$ & $6(15.3 \%)$ & $8(20.4 \%)$ & $6(15.3 \%)$ & $20(51.2 \%)$ \\
\hline Nocardia & & & $1(2.3 \%)$ & $1(2.3 \%)$ & & & & \\
\hline Culture negative & $2(4.6 \%)$ & $1(2.3 \%)$ & & $3(6.9 \%)$ & $3(7.6 \%)$ & $1(2.5 \%)$ & & $4(10.2 \%)$ \\
\hline
\end{tabular}

${ }^{*}$ None of these differences is significant at $P<.05$.

tSome infections were polymicrobial.

National Nosocomial Infections Surveillance System for CABG operations (chest and leg) among patients in risk category $2 .{ }^{17}$ The significance of the differences between the two groups was determined by the Student $t$ test or Wilcoxon rank-sum test for continuous variables and by the Fisher exact test or $\chi^{2}$ test for categoric variables. Calculation was performed with the SPSS statistical program version 9 (SPSS Inc, Chicago, Ill).

\section{Results}

\section{Characteristics of Patients}

Between January 1997 and December 1999 a total of 1032 patients were considered eligible and enrolled in the trial. Of these 144 were excluded, 123 because of deviations from the antibiotic regimens (110 received both drugs included in the trial and 13 did not receive the drug indicated by the random assignment) and 21 because of incomplete follow-up. Eventually 885 patients completed the trial; 452 received vancomycin and 433 received cefazolin. The two groups were similar with respect to patient characteristics, type of surgery, duration of operation, risk index categories, duration of preoperative hospitalization, and timing of prophylaxis administration (Table 1).

\section{Outcomes}

The outcomes of patients in both groups, including SSIs, are shown in Table 2. There were 43 SSIs in the vancomycin group and 39 SSIs in the cefazolin group (overall SSI rates of $9.5 \%$ and $9.0 \%$, respectively, $P=.8$ ). The observed superficial and deep incisional SSI rates in the vancomycin group were $5.5 \%$ and $2.6 \%$, respectively, as compared with rates of $4.6 \%$ and $1.6 \%$, respectively, in the cefazolin group ( $P=.6$ and $P=.4$, respectively). Most organ-space infections in both groups were mediastinitis. Although organ-space infections were twice as frequent in the cefazolin group as in the vancomycin group (12 cases, $2.7 \%$, vs. 6 cases, $1.3 \%$ ), this difference did not reach statistical significance $(P=.1)$.

The durations of the postoperative hospitalization and mortalities were similar in the two groups. The overall infection rates were also similar according to the length of stay in the hospital before surgery. In the vancomycin group there were 35 SSIs among 385 patients hospitalized for 6 days or less before the operation and 8 SSIs among 67 patients with preoperative stays of 7 days or longer (9\% vs $11.9 \%, P=.6)$. In comparison, in the cefazolin group there were 30 SSIs among 357 patients with stays of 6 days or less before the operation and 9 SSIs among 76 patients with preoperative stays of 7 days or longer $(8.4 \%$ vs $11.8 \%, P=.4)$.

Table 3 summarizes the distribution of pathogens isolated in both groups of patients according to the different types and sites of SSI. Pathogens isolated from SSIs were similarly distributed in both groups, although some differences were found that did not reach statistical significance. More than $60 \%$ of SSIs were due to gram-positive cocci. $S$ aureus was the leading pathogen, closely followed by coagulase-negative staphylococci. Gram-negative bacilli caused approximately $50 \%$ of SSIs. Nevertheless, there was a trend toward more common infections with $\beta$-lactam-resistant 
TABLE 4. Pathogens isolated from BSIs among 38 patients receiving vancomycin or cefazolin prophylaxis in cardiovascular surgery

\begin{tabular}{|c|c|c|c|c|}
\hline & \multicolumn{2}{|c|}{$\begin{array}{c}\text { Vancomycin } \\
(\mathrm{n}=\mathbf{2 0}) \\
\end{array}$} & \multicolumn{2}{|c|}{$\begin{array}{l}\text { Cefazolin } \\
\text { (n = 18) }\end{array}$} \\
\hline & No. & $\%$ & No. & $\%$ \\
\hline \multicolumn{5}{|l|}{ Gram-positive cocci } \\
\hline All & 12 & 60 & 10 & 55.5 \\
\hline Methicillin-susceptible $S$ aureus & 6 & 30 & 2 & 11.1 \\
\hline Methicillin-resistant $S$ aureus & 2 & 10 & 4 & 22.2 \\
\hline $\begin{array}{l}\text { Methicillin-susceptible coagulase- } \\
\text { negative staphylococci }\end{array}$ & 1 & 5 & 0 & 0 \\
\hline $\begin{array}{l}\text { Methicillin-resistant coagulase- } \\
\text { negative staphylococci }\end{array}$ & 2 & 10 & 2 & 11.1 \\
\hline Enterococci & 1 & 5 & 2 & 11.1 \\
\hline \multicolumn{5}{|l|}{ Gram-negative bacilli } \\
\hline All & 11 & 55 & 7 & 38.8 \\
\hline Klebsiella species & 6 & 30 & 3 & 16.6 \\
\hline Enterobacter species & 2 & 10 & 0 & 0 \\
\hline Serratia species & 2 & 10 & 1 & 5.5 \\
\hline Others & 1 & 5 & 3 & 16.6 \\
\hline \multicolumn{5}{|l|}{ Fungi } \\
\hline Calbicans & 0 & & 2 & 11.1 \\
\hline
\end{tabular}

No differences were significant at $P<.05$. Some infections were polymicrobial.

gram-positive cocci (eg, MRSA and methicillin-resistant enterococci) in the cefazolin group (18 of 433 patients, $4.2 \%$, vs 9 of 452 patients, $2 \%, P=.09$ ). In contrast, SSIs due to methicillin-susceptible $S$ aureus and coagulase-negative staphylococci were significantly more frequent among patients who received vancomycin prophylaxis (17 of 452 patients, $3.7 \%$, vs 6 of 433 patients, $1.3 \%, P=.04)$. The mean preoperative stays among patients with SSIs caused by methicillin-susceptible staphylococci and by MRSA were similar $(4.65 \pm 5.0$ days vs $5.7 \pm 10.5$ days, $P=.7)$. Polymicrobial infection rates were also similar in the two groups; 8 of 43 infections (18.6\%) in the vancomycin group were polymicrobial, as compared with 11 of 39 infections $(28.2 \%)$ in the cefazolin group $(P=.4)$.

Of the 38 cases of bloodstream infection (BSI) that occurred during the study, $20(4.4 \%)$ were observed in the vancomycin group and $18(4.1 \%)$ were seen in the cefazolin group $(P=.9)$. In both groups BSIs were significantly more common among patients with SSIs than among those without SSIs. In the vancomycin group 9 BSIs occurred among 43 patients with SSIs (20.9\%), as compared with 11 BSIs observed in 409 patients $(2.6 \%)$ without SSIs $(P<.001)$. In the cefazolin group there were 9 BSIs among 39 patients with SSIs (23\%), as compared with 9 BSIs among 394 patients $(2.2 \%)$ without SSIs $(P<.001)$. BSIs occurred only among patients with chest infections. Pathogens isolated in cases of BSI are shown in Table 4.

\section{Discussion}

Worldwide the cephalosporin antibiotics, in particular the first- and second-generation agents, are the most widely used drugs in surgical practice, including in cardiac surgery. ${ }^{18,19}$ Despite a relatively large number of studies, no cephalosporin drug has emerged as clearly superior to the others in reducing SSI rates. A meta-analysis of antibiotic prophylaxis that included six studies of cefazolin versus cefamandole or cefuroxime ${ }^{20}$ concluded that the secondgeneration cephalosporins were associated with lower prevalence of wound infection than seen with cefazolin. However, subsequent randomized double-blind trials failed to show the superiority of cefamandole or cefuroxime over first-generation cephalosporins in cardiac surgery. ${ }^{10,21}$ The use of vancomycin for prophylaxis in cardiac surgery, although much more controversial, might be justified in the light of many observations. First, organ-space infections, although infrequent, have devastating consequences. Second, coagulase-negative staphylococci and $S$ aureus, the most important pathogens responsible for SSIs in cardiac surgery, are frequently resistant to $\beta$-lactam antibiotics. Third, some studies have shown that more than $80 \%$ of surgical patients who receive a first-generation cephalosporin for prophylaxis become colonized with methicillin-resistant coagulase-negative staphylococci by the seventh postoperative day. ${ }^{22,23}$ Finally, the superiority of vancomycin over cephalosporins in cardiac surgery has been suggested in two previous studies. Maki and colleagues ${ }^{10}$ showed in a prospective, double-blind trial that vancomycin, relative to cefazolin and cefuroxime, was associated with a statistically significant reduction in the rate of thoracic surgical SSIs other than mediastinitis. In addition, the mean duration of postoperative hospitalization in the vancomycin group was significantly reduced relative to that observed in the cefazolin group. In a preliminary report, Nafziger and colleagues ${ }^{24}$ showed that prophylaxis with a first-generation cephalosporin instead of vancomycin appeared to be a risk factor for mediastinitis.

On the other hand, two major problems with the prophylactic use of vancomycin in surgery should be seriously considered. First, several studies have concluded that the use of vancomycin prophylaxis in cardiac and noncardiac surgery may result in serious untoward effects, particularly hypotension. ${ }^{25,26}$ Second, and more important, are the alarming problems of vancomycin-resistant enterococci ${ }^{27}$ and more recently glycopeptide-intermediate-resistant $S$ aureus. ${ }^{28}$ Reports of these emerging resistances have significantly altered attitudes toward the use of vancomycin prophylaxis in surgery. As a consequence, recent guidelines for prevention of SSIs strongly recommend avoiding the routine use of vancomycin 
for antimicrobial prophylaxis in surgery. ${ }^{29}$ These recommendations may be strengthened by a recently published trial ${ }^{30}$ that showed similar results when vancomycin and cefuroxime were used for antimicrobial prophylaxis in CABG.

The major objective of our trial was to investigate whether SSI rates associated with cardiac surgery could be reduced by the use of vancomycin prophylaxis in an institution with a high prevalence of MRSA infections. Although we observed a trend toward more serious infections occurring among patients who received cefazolin prophylaxis, this trend did not reach statistical significance. As could be expected, SSIs caused by methicillin-resistant gram-positive cocci were more common among patients who received cefazolin prophylaxis. However, the overall results were counterbalanced by the fact that infections with methicillin-susceptible staphylococci were significantly more frequent in the vancomycin group. Paradoxically, infections with gram-negative bacilli were equally common in the two groups.

Although a prolonged preoperative stay is a likely surrogate for severity of illness, it is frequently suggested as a patient characteristic associated with increased SSI risk. ${ }^{29}$ Moreover, infections with resistant organisms, including MRSA, are typically hospital acquired. Therefore one could make a point in favor of the use of vancomycin as surgical prophylaxis for patients with a prolonged preoperative stay. In this study, however, SSI rates and infections with MRSA were not affected by a more prolonged preoperative stay. Thus our results do not support the use of vancomycin prophylaxis in this setting.

It appears that the random assignment achieved a good balance among the various covariates of the two groups (Table 1). Nevertheless, the fact that the trial could not be performed in a double-blinded fashion represents an important limitation of this study. Taking this limitation in consideration, we conclude that this study could not show any clear advantage of vancomycin over cefazolin in reducing SSI rates in cardiac surgery at our institution, where the prevalence of MRSA infections is high. Possible explanations may include the superiority of cefazolin over vancomycin in preventing infections with $\beta$-lactam-susceptible organisms or the possibility that some serious infections complicating cardiac operations are initiated after the operation in a critical care setting, rather than being acquired during operation. ${ }^{31,32}$ Our data appear to support the continuing efforts to restrict the prophylactic use of vancomycin in surgical practice.

\section{References}

1. Burke JP. Infections of cardiovascular prostheses. In: Bennett JV, Brachman PS, editors. Hospital Infections. 4th ed. Philadelphia: Lippincott-Raven; 1998. p. 599-612.

2. American Heart Association. Heart and stroke facts. 1995 statistical supplement. Dallas: The Association; 1995.
3. Goodman JS, Schaffner W, Collins HA, Battersby EJ, Koenig MG. Infection after cardiovascular surgery. N Engl J Med. 1968;278:117-23.

4. Fekety FR, Cluff LE, Sabiston DC, Seidl LG, Smith JW, Thoburn R. A study of antibiotic prophylaxis in cardiac surgery. $J$ Thorac Cardiovasc Surg. 1969;57:757-63.

5. Fong IW, Baker CB, McKee DC. The value of prophylactic antibiotics in aorta-coronary bypass operations. J Thorac Cardiovasc Surg. 1979;78:908-13.

6. Austin TW, Coles JC, Burnett R, Goldbach M. Aortocoronary bypass procedures and sternotomy infections: a study of antistaphylococcal prophylaxis. Can J Surg. 1980;23:483-5.

7. Curtis JJ, Boley TM, Walls JT, Hamory B, Schmaltz RA. Randomized, prospective comparison of first- and second-generation cephalosporins as infection prophylaxis for cardiac surgery. Am J Surg. 1993;166:734-7.

8. Kaiser AB, Petracek MR, Lea JW, Kernodle DS, Roach AC, Alford WC, et al. Efficacy of cefazolin, cefamandole, and gentamicin as prophylactic agents in cardiac surgery. Results of a prospective, randomized, double-blind trial in 1030 patients. Ann Surg. 1987;206:791-7.

9. Dellinger EP, Gross PA, Barrett TL, Krause PJ, Martone WJ, McGowan JE, et al. Quality standard for antimicrobial prophylaxis in surgical procedures. Infectious Diseases Society of America. Clin Infect Dis. 1994;18:422-7.

10. Maki DG, Bohn MJ, Stolz SM, Kroncke GM, Acher CW, Myerowitz PD. Comparative study of cefazolin, cefamandole and vancomycin for surgical prophylaxis in cardiac and vascular operations: double-blind randomized trial. J Thorac Cardiovasc Surg. 1992;104:1423-34.

11. Finkelstein R, Markel A, Reinherz G, Hashman N, Merzbach D. The emergence of methicillin-resistant Staphylococcus aureus infections in an Israeli hospital. $J$ Hosp Infect. 1989;14:55-61.

12. Wenzel RP, Reagan DR, Bertino JS Jr, Baron EJ, Arias K. Methicillinresistant Staphylococcus aureus outbreak: a consensus panel's definition and management guidelines. Am J Infect Control. 1998;26: $102-10$.

13. Classen DC, Evans RS, Pestotnik SL, Horn SD, Menlove RL, Burke JP. The timing of administration of antibiotics and the risk of surgicalwound infection. N Engl J Med. 1992;326:281-6.

14. Garner JS, Jarvis WR, Emori TG, Horan TC, Hughes JM. CDC definitions of nosocomial infections. In: Olmsted RN, editor. APIC infection control and applied epidemiology: principles and practice. St Louis: Mosby; 1996. p. A1-A20.

15. Durack DT, Lukes AS, Bright DK. New criteria for diagnosis of infective endocarditis: utilization of specific echocardiographic findings. Duke Endocarditis Service. Am J Med. 1994;96:200-9.

16. Culver DH, Horan TC, Gaynes RP, Martone WJ, Jarvis WR, Emori TG, et al. Surgical wound infection rates by wound class, operative procedure, and patient risk index. National Nosocomial Infections Surveillance System. Am J Med. 1991;91 Suppl 3B:152S-7S.

17. National Nosocomial Infections Surveillance System. National Nosocomial Infections Surveillance (NNIS) report, data summary from October 1986-April 1997, issued May 1997: a report from the NNIS System. Am J Infect Control. 1997;25:477-87.

18. Gorbach SL. The role of cephalosporins in surgical prophylaxis. $J$ Antimicrob Chemother. 1989;23 Suppl D:61-70.

19. Antimicrobial prophylaxis in surgery. Med Lett Drugs Ther. 1997;39: 97-101

20. Kreter B, Woods M. Antibiotic prophylaxis for cardiothoracic operations: metaanalysis of thirty years of clinical trials. J Thorac Cardiovasc Surg. 1992;104:590-9.

21. Townsend TR, Reitz BA, Bilker WB, Bartlett JG. Clinical trial of cefamandole, cefazolin, and cefuroxime for antibiotic prophylaxis in cardiac operations. J Thorac Cardiovasc Surg. 1993;106:664-70.

22. Archer GL, Armstrong BC. Alterations of staphylococcal flora in cardiac surgery patients receiving antibiotic prophylaxis. $J$ Infect Dis. 1983;147:642-9.

23. Kernodle DS, Barg NL, Kaiser AB. Low-level colonization of hospitalized patients with methicillin-resistant coagulase-negative staphylococci and emergence of the organisms during surgical antimicrobial prophylaxis. Antimicrob Agents Chemother. 1988;32:202-8.

24 Nafziger DA, Perl TM, Herwaldt LA, Kuhn KR, Hollis RA, Wenzel 
RP. Mediastinitis at a tertiary referral hospital [abstract 34]. In: Program and abstracts of the 32nd Interscience Conference on Antimicrobial Agents and Chemotherapy; 1992 Oct; Anaheim (CA). Washington, DC: American Society for Microbiology; 1992. p. 320.

25. Romanelli VA, Howie MB, Myerowitz PD, Zvara DA, Rezaei A, Jackman DL, et al. Intraoperative and postoperative effects of vancomycin administration in cardiac surgery patients: a prospective, double-blind, randomized trial. Crit Care Med. 1993;21:1124-31.

26. Odio C, Mohs E, Sklar FH, Nelson JD, McCracken GH. Adverse reactions to vancomycin used as prophylaxis for CSF shunt procedures. Am J Dis Child. 1984;138:17-9.

27. National Nosocomial Infections Surveillance System. Nosocomial enterococci resistant to vancomycin-United States, 1989-1993. MMWR Morb Mortal Wkly Rep. 1993;42:597-9.

28. Smith TL, Pearson ML, Wilcox KR, Cruz C, Lancaster MV,
Robinson-Dunn B, et al. Emergence of vancomycin resistance in Staphylococcus aureus. N Engl J Med. 1999;340:493-501.

29. Mangram AJ, Horan TC, Pearson ML, Silver LC, Jarvis WR Guideline for prevention of surgical site infection, 1999. Hospital Infection Control Practices Advisory Committee. Infect Control Hosp Epidemiol. 1999;20:250-78.

30. Vuorisalo S, Pokela R, Syrjälä H. Comparison of vancomycin and cefuroxime for infection prophylaxis in coronary artery bypass surgery. Infect Control Hosp Epidemiol. 1998;19:234-9.

31. Lowry PW, Blankenship RJ, Gridley W, Troup NJ, Tompkins LS. A cluster of Legionella sternal-wound infections due to postoperative topical exposure to contaminated tap water. $N$ Engl J Med. 1991;324:109-13.

32. Ehrenkranz NJ, Pfaff SJ. Mediastinitis complicating cardiac operations: evidence of postoperative causation. Rev Infect Dis. 1991;13 803-14.

Access to The Journal of Thoracic and Cardiovascular Surgery Online is reserved for print subscribers!

Full-text access to The Journal of Thoracic and Cardiovascular Surgery Online is available for all print subscribers. To activate your individual online subscription, please visit The Journal of Thoracic and Cardiovascular Surgery Online, point your browser to http://www.mosby.com/jtcvs, follow the prompts to activate your online access, and follow the instructions. To activate your account, you will need your subscriber account number, which you can find on your mailing label (note: the number of digits in your subscriber account number varies from 6 to 10). See the example below in which the subscriber account number has been circled:

\section{Sample mailing label}

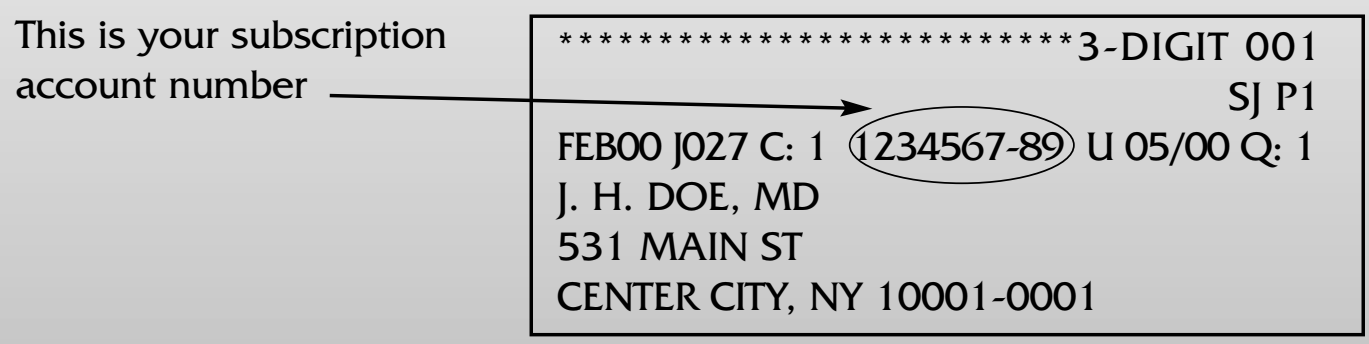

Personal subscriptions to The Journal of Thoracic and Cardiovascular Surgery Online are for individual use only and may not be transferred. Use of The Journal of Thoracic and Cardiovascular Surgery Online is subject to agreement to the terms and conditions as indicated online. 